\title{
Expression of Survivin Gene and Protein in Mycosis Fungoides
}

\author{
Hanan $\mathrm{Nada}^{1,2^{*}}$, Laila Rashed ${ }^{2}$ and Solafa Amin ${ }^{2}$ \\ ${ }^{1}$ Soliman Fakeeh Hospital, Saudi Arabia \\ ${ }^{2}$ Department of Dermatology, Biochemistry and Pathology, Cairo University, Egypt
}

*Corresponding author: Hanan Nada, Soliman Fakeeh Hospital, Saudi Arabia and Department of Dermatology, Biochemistry and Pathology, Cairo University, Tel: 002 01023000226; E-mail: hananrnada.dermato@gmail.com

Received date: Feb 17, 2016, Accepted date: Mar 29, 2016, Published date: Apr 06, 2016

Copyright: (c) $2016 \mathrm{Nada} \mathrm{H}$, et al. This is an open-access article distributed under the terms of the Creative Commons Attribution License, which permits unrestricted use, distribution, and reproduction in any medium, provided the original author and source are credited.

\section{Abstract}

Background: Survivin is a member of the inhibitors of apoptosis gene family that has been implicated in cell division and suppression of apoptosis that becomes expressed in human cancers, e.g. colorectal, bladder cancers. But, there is no available data on the role of survivin in cutaneous neoplasms.

Aim: To estimate the expression of survivin gene and protein in Mycosis Fungoides (MF).

Methods: Seventeen cases of MF have been en-rolled into this study. Skin biopsies from such patient were subjected to RT-PCR technique to detect the level of survivin gene and protein.

Results: There was significant increase in expression of surviving gene and protein in cases of MF if compared to normal control.

Conclusion: Survivin may have a role in induction of MF and this may influence the therapeutic strategies for the treatment of MF.

Keywords: Survivin; Mycosis fungoides

\section{Introduction}

Programmed cell death, or apoptosis, is essential for embryonic development and the homeostasis of adult organisms [1]. This involves a dynamic coupling of apoptotic pathways to checkpoint mechanisms that survey cell cycle transitions and eliminate potentially dangerous cells before they progress through mitosis [2]. Molecules functioning at the checkpoint interface between cell proliferation and cell survival, such as p53, are essential to preserve genomic integrity, and their deregulation is a hallmark to cancer [3].

Survivin is a member of the Inhibitor of Apoptosis (IAP) 1 gene family that has been implicated in cell division and suppression of apoptosis and becomes dramatically overexpressed in cancer in response to oncogene activation [4], loss of p53 or deregulated transcription of patterning pathways $[5,6]$. Although the function of survivin has been dubbed as controversial in the past [7], available published evidence has shown remarkable agreement in assigning a dual role of this protein in mitotic control and inhibition of apoptosis. Despite the wealth of information accumulated on survivin, precisely how this pathway couples to the cell death and cell division machineries has not been completely elucidated [8].

Structural data and analysis of caspase catalytic activity indicate that the cytoprotective function of survivin may not conform the paradigm of other IAP family proteins as endogenous caspase inhibitors. Similarly a proposed evolutionary conserved role of surviving in late stage mitosis, or cytokinesis $[9,10]$, has been contrasted by data suggesting a broader role at cell division, involving centrosome function [11], spindle checkpoint and microtube dynamics [12]. It also functions at multiple phases of mitosis and in the control of mitochondrial-dependent apoptosis and produces a mitotic arrest followed by re-entry into cell-cycle and polyploidy C. Adding further complexity, survivin has been shown to exist in immunocellular functions [13], and two alternatively spliced surviving isoforms have been described [14].

Dysregulation of apoptosis may favor onset and progression of cancer and influence response to therapy. Survivin is an inhibitor of apoptosis that is electively overexpressed in common human cancers, but not in normal tissues, and that correlates with aggressive disease and unfavorable out-comes [15]. Although the bulk of previous studies has shown the involvement of other apoptosis regulators, including p53 and bcl-x1, in tumour progression, inhibition of apoptosis by survivin, alone or in combination with bcl-2, may significantly influence the outcome of colorectal cancer and translate into considerably shorter survival rates [16-18]. Survivin was found in $78 \%$ of bladder cancers, but not in normal urothelium, and its expression correlated with accelerated recurrences [15]. Also, it has been found that survivin gene is expressed in Neuroblastoma and this expression correlates with a more aggressive and histologically unfavourable disease outcome [19]. Unfortunately, the role of survivin in cutaneous neoplasms has not been highlighted yet. The aim of this study is to investigate the expression of this novel apoptosis inhibitor gene and protein in one of important cutaneous neoplasms; Mycosis Fungoides (MF).

\section{Patients and Methods}

This study was conducted on 17 cases (10 males and 7 females), suffering from Mycosis Fungoides (Patch and Plaque type; Stage 1a, 1b 
Page 2 of 6

and Stage II a). Their ages ranged from 17 to 63 years old. Their duration of disease ranged between 6 months to 2 years. The distribution of their lesions varied; in 2 cases, the lesions were located in the abdomen, 2 cases in the upper limbs, 3 cases in the back, 3 cases in the chest, in 2 cases, the lesions involved the whole trunk, in 2 cases the lesions involved the trunk and thighs, while the remaining 1 case, the lesions were present in the thigh and upper limb. The size of the lesions varied, the smallest sized lesion was $1 \times 1 \mathrm{~cm}$ while the largest one was $5 \times 10 \mathrm{~cm}$. Studied cases were chosen as they didn't use any treatment 6 weeks prior to the study.

Five healthy normal volunteers were enrolled into this study as a control; their ages ranged between 20 up to 43 years old.

For all cases of MF; Complete Blood Count, Liver and Kidney function tests, abdomen pelvic ultrasonography and chest X-ray were performed.

For all cases and control cases Skin Biopsy was performed then was sent for:

- Hematoxylin and Eosin stain to confirm the diagnosis of MF.

- Detection of Survivin Gene expression and Survivin Protein level as follows:

Gene expression of survivin by RT-PCR: About $30 \mathrm{mg}$ of skin tissue (biopsy) was homogeized then centrifuged at 10,000 rpm for $15 \mathrm{~min}$., the supernatant was examined for the detection of surviving gene.

RNA extraction: Total RNA was extracted from tissue homogenate by acid guindium thiocyanate phenol-chloroform then extracted RNA was quantitated by spectrophotometer at $260 \mathrm{~nm}$ [20].

RT-PCR: $5 \mu$ g of total RNA was reverse transcribed using $12.5 \mu \mathrm{l}$ of oligo dt primer and was denaturated at $70^{\circ} \mathrm{C}$ for 2 min. then RT mixture containing $50 \mathrm{mM}$ tris HCL pH $8.3,50 \mathrm{mMKcL}, 0.5 \mathrm{mM}$ dNTPs 200 unit of MMLV reverse transciptase was added then the reaction was placed at $42^{\circ} \mathrm{C}$ for 1 hour then $95^{\circ} \mathrm{C}$ for $5 \mathrm{~min}$. to stop the reaction.

PCR was performed by adding PCR mix containing 10mMHCL PH $8.3,10 \mathrm{mM}$ dNTPs, 2.5 unit tag polymerase and $100 \mu \mathrm{M}$ of each specific surviving primer with the following sequence:

\section{Forward: 5'- CTT CCT CCC TCA GCC TCC - 3'}

\section{Reverse: 5' - AAT CCC AGC ACT TTC AT - 3'}

Then the reaction mixture was subjected to 40 cycles of $95^{\circ} \mathrm{C}$ for 7 $\min$., $55^{\circ} \mathrm{C}$ for $1 \mathrm{~min}$ and $72^{\circ} \mathrm{C}$ for $2 \mathrm{~min}$. after the last cycle a final extension at $72^{\circ} \mathrm{C}$ for $10 \mathrm{~min}$. was done.

Agarose gel electrophoresis: All the PCR products were electrophoresed on $2 \%$ agarose gel stained with ethidium bromide and visualized by UV transilluminator
Gel documentation: The PCR products were semi quantitated using the gel documentation system (BIO DOC Analyze) supplied by Biometra.

Measurement of survivin protein level: The level of survivin was detected in tissue homogenate by using Ezyme Linked Immuno Sorbent Assay (ELISA) kit which supplied by Biosource International, Inc., USA according to manufacturers instruction [21].

\section{Results}

Seventeen cases were subjected to this study; ten males (58.8\%) and seven females $(41.2 \%)$. Their mean ages were $(35.41 \pm 15.464)$ and their mean duration of the illness was $(12.82 \pm 5.703)$. The mean size of lesions was $4.32 \pm 2.506$ ), and these lesions were either single in (23.5\%) of cases or multiple in $(76.5 \%)$ of cases. Their site varied, in the back in $17.6 \%$ of cases, in the chest in $17.6 \%$ of cases, in upper limb in $17.6 \%$ of cases, in the abdomen in $11.8 \%$ of cases, in the trunk and thigh in $11.8 \%$ of cases, and in the lower limb in $5.9 \%$ of cases. The mean of the extent of body surface area involvement was $(76.5 \pm 23.5)$.

There was no significant correlation between age of the patients and size of the lesion $(\mathrm{P}=0.377)$ or age and duration of the disease $(\mathrm{P}=0.097)$, but there was significant correlation between size of the lesion and duration of the disease $(\mathrm{P}=0.037)$.

Survivin gene expression level was measured in these cases. The minimum level was $196.8 \mu \mathrm{g} / \mathrm{mg}$, the maximum level was $301.2 \mu \mathrm{g} / \mathrm{mg}$ and mean level was $245.235 \pm 1.4928$.

Survivin protein level was also measured in the same cases. Its minimum level was $109.2 \mathrm{ng} / \mathrm{m}$, the maximum level was $156.8 \mathrm{ng} / \mathrm{ml}$. and mean level was $134.847 \pm 13.3513$.

In control cases, survivin gene expression was found to range between 153.4 and $212.5 \mu \mathrm{g} / \mathrm{mg}$ with mean level $(181.98 \pm 22.68)$. While survivin protein level was found to range between 82.9 and 106 $\mathrm{ng} / \mathrm{ml}$ with mean level $(94.68 \pm 10.93)$.

Comparing cases to controls, there was a significant difference between cases and control both in survivin gene and survivin protein levels $(\mathrm{P}=0-000)$. The level of survivin was higher in cases than controls.

The level of survivin gene expression varied according to the site of the lesion. The highest level was found in the back lesion (mean: 273.90 \pm 10.55 ) followed by the upper limb lesion (mean: $249.00 \pm 52.20$ ), trunk and thigh lesion (mean: $247.90 \pm 19.65)$, trunk lesion (mean: $244.36 \pm 36.97$ ), lower limb (mean: 238.70), abdomen (mean: $237.40 \pm$ $33.65)$ and the least level was found in the chest (mean: $219.30 \pm 24.85$ ) (Table 1).

\begin{tabular}{|c|c|c|c|c|c|c|}
\hline \multirow{2}{*}{ Site } & \multicolumn{3}{|c|}{ Survivin gene expression } & \multicolumn{3}{|c|}{ Survivin protein level } \\
\hline & Minimum & Maximum & Mean SD & Minimum & Maximum & Mean SD \\
\hline Abdomen: 3 cases & 213.6 & 261.2 & $237.4 \pm 33.65$ & 136.8 & 138 & $137.4 \pm 0.84$ \\
\hline Back: 3 cases & 263.4 & 284.5 & $273.9 \pm 10.55$ & 123.8 & 132 & $126.8 \pm 4.52$ \\
\hline Chest: 3 cases & 198.2 & 246.7 & $219.3 \pm 24.85$ & 127.6 & 142.5 & $133.5 \pm 7.91$ \\
\hline Lower limb: 1 case & 238.7 & 238.7 & $238.7 \pm 00.00$ & 156.8 & 156.8 & $156.8 \pm 00.00$ \\
\hline
\end{tabular}




\begin{tabular}{|l|l|l|l|l|l|l|}
\hline Trunk: 3 cases & 201.8 & 268.5 & $244.36 \pm 36.97$ & 123.9 & 152.8 & $140.9 \pm 15.10$ \\
\hline Trunk \& thigh: 2 cases & 234 & 261.8 & $247.9 \pm 19.65$ & 124.2 & 143.5 & $133.85 \pm 13.64$ \\
\hline Upper limb: 3 cases & 196.8 & 301.2 & $249.0 \pm 52.2$ & 109.2 & 156.3 & $129.83 \pm 24.08$ \\
\hline
\end{tabular}

Table 1: Level of survivin gene expression and survivin protein level in cases of MF.

The level of survivin protein also varied according to the site of the lesion. Its level was highest in the lower limb lesions (156.8), then in the trunk $(140.90 \pm 15.10)$, the abdomen $(137.40 \pm 0.84)$, trunk and thigh (133.85 \pm 13.64$)$, chest lesion (133.50 \pm 7.91$)$, upper limb lesion $(129.83 \pm 24.08)$ and the least level was found in the back lesion $(126.80 \pm 4.52)$ (Table 1$)$.
The level of survivin gene expression varied according to the number of the lesion. The mean level in multiple lesions was $(245.80 \pm$ $27.72)$ while in single lesion was $(243.40 \pm 46.99)$. Also the level of survivin protein varied with the number of the lesions. The mean level in multiple lesions was $(133.85 \pm 13.83)$ while in single lesion was (138.07 \pm 12.92) (Table 2).

\begin{tabular}{|l|l|l|l|l|l|l|}
\hline & \multicolumn{2}{l}{ Survivin gene expression } & \multicolumn{2}{l|}{ Survivin protein level } \\
\cline { 2 - 7 } & Minimum & Maximum & Mean SD & Minimum & Maximum & Mean SD \\
\hline Single lesion & 198.2 & 301.2 & $243.40 \pm 46.99$ & 127.6 & 156.3 & $138.07 \pm 12.92$ \\
\hline Multiple lesions & 196.8 & 284.5 & $245.80 \pm 27.72$ & 109.2 & 156.8 & $133.85 \pm 13.85$ \\
\hline
\end{tabular}

Table 2: Level of survivin gene and protein in relation to number of the lesion.

The level of survivin gene expression varies according to the sex of the enrolled patients. In males, the mean level was $(253.28 \pm 21.23)$ while in females, it was $(233.74 \pm 41.30)$. The level of survivin protein also varied with patient sex. In males, the mean level was $(135.47 \pm$ $12.55)$ while in females it was $(133.95 \pm 15.41)$ (Table 3$)$.

\begin{tabular}{|l|l|l|l|l|l|l|}
\hline & \multicolumn{2}{l}{ Survivin gene expression } & \multicolumn{2}{l|}{ Survivin protein level } \\
\cline { 2 - 7 } & Minimum & Maximum & Mean SD & Minimum & Maximum & Mean SD \\
\hline Single lesion & 198.2 & 301.2 & $243.40 \pm 46.99$ & 127.6 & 156.3 & $138.07 \pm 12.92$ \\
\hline Multiple lesions & 196.8 & 284.5 & $245.80 \pm 27.72$ & 109.2 & 156.8 & $133.85 \pm 13.85$ \\
\hline
\end{tabular}

Table 3: Level of survivin gene and protein in relation to sex of the patient.

There was no significant correlation between the level of survivin gene expression and the age of the patient $(\mathrm{P}=0.272)$, size of the lesion $(\mathrm{P}=0.169)$ or duration of the disease $(\mathrm{P} 0.583)$. There was no significant correlation between the level of survivin protein and the age of the patient $(\mathrm{P}=0.837)$ or size of the lesion $(\mathrm{P}=.0 .952)$. But there was significant correlation between the level of survivin protein and duration of the disease $(\mathrm{P}=0.025)$. On the other hand; there was no significant correlation between survivin gene expression and survivin protein level in the studied cases $(\mathrm{P}=0.409)$ (Table 4$)$.

\begin{tabular}{|c|c|c|}
\hline & $\begin{array}{l}\text { Survivin } \\
\text { expression }\end{array} \quad$ gene & Survivin protein level \\
\hline Age & $\begin{array}{l}\mathrm{P}=0.272 \quad \text { (not } \\
\text { significant) }\end{array}$ & $\begin{array}{l}\mathrm{P}=0.837 \text { (not } \\
\text { significant) }\end{array}$ \\
\hline Size of the lesion & $\begin{array}{l}\mathrm{P}=0.169 \quad \text { (not } \\
\text { significant) }\end{array}$ & $\begin{array}{l}\mathrm{P}=0.952 \quad \text { (not } \\
\text { significant) }\end{array}$ \\
\hline Duration of the disease & $\begin{array}{l}\mathrm{P}=0.583 \quad \text { (not } \\
\text { significant) }\end{array}$ & $P=0.025$ (significant) \\
\hline Survivin gene expression & & $\begin{array}{l}\mathrm{P}=0.409 \text { (not } \\
\text { significant) }\end{array}$ \\
\hline
\end{tabular}

\begin{tabular}{|l|l|l|}
\hline Survivin protein level & $\begin{array}{l}\mathrm{P}=0.409 \quad \text { (not } \\
\text { significant) }\end{array}$
\end{tabular}

Table 4: Level of survivin gene and protein in relation to age of patients, size of lesion, duration of disease, NB: Correlation is significant at the 0.05 level.

\section{Statistical analysis}

Descriptive statistics were performed for all variables of the study. For the quantitative variables, the range, mean, $\pm S D$, and \pm SEM were calculated. For categorical variables, absolute counts and percentages were generated.

A comparison of quantitative data was tested using the 'Student $t$ test' to compare two groups and the 'paired t-test' to compare the affected and the unaffected sites in the same group. A comparison of categorical data was performed using the $\chi 2$-test. A correlation study to establish the relationship between different variables was conducted using the Pearson correlation coefficient 'r.' The P-value was considered significant when it was less than or equal to 0.05 . The statistical program used was SPSS, version 14 (SPSS Chicago, Illinois, USA). 


\section{Discussion}

Inhibitors of programmed cell death (apoptosis) may regulate tissue differentiation and aberrantly promote cell survival in neoplasia. A novel apoptosis inhibitor of the of the IAP gene family, designated survivin, was recently found in all of the most common human cancers but not in normal, terminally differentiated adult tissues. The expression of survivin in embryonic and fetal development was investigated. Immunohistochemistry and in situ hybridization studies demonstrated strong expression of survivin in several apoptosisregulated fetal tissues, including the stem cell layer of stratified epithelia, endocrine pancreas, and thymic medulla, with a pattern that did not overlap with that of another apoptosis inhibitor, bcl-2. A sequence-specific antibody to survivin immunoblotted a single - 16.5kd survivin band in human fetal lung, liver, heart, kidney, and gastrointestinal tract. In mouse embryo, prominent and nearly ubiquitous distribution of survivin was found at embryonic day (E) 11.5 , whereas at E15 to -21 , survivin expression restricted to the distal bronchiolar epithelium of the lung and neural-crest-derived cells, including dorsal root ganglion neurons, hypophysis, and the coroid plexus. These data suggest that expression of survivin in embryonic and fetal development may contribute to tissue homeostasis and differentiation independently of bcl-2. Aberrations of this developmental pathway may result in prominent re-expression of survivin in neoplasia and abnormally prolonged cell viability [22].

Regulation of cell proliferation by programmed cell death (apoptosis) contributes to tissue and organ homeostasis during development and differentiation [23]. This process involves an evolutionarily conserved multistep cascade and is controlled by proteins that promote or control apoptotic cell death [24]. Specifically, inhibitors of apoptosis, most notably of the bcl-2 family, maintain lymphoid homeostasis and morphogenesis in adult and fetal tissues [25-27]. Deregulated expression of bcl-2 has also been implicated in cancer, by aberrantly prolonging cell survival and facilitating the insurgence of transforming mutations $[25,26]$.

In addition to bcl-2, a novel class of apoptosis inhibitors related to the Baulovirus IAP gene has been recently identified in human, mouse, and Drosophila [28]. Highly evolutionarily conserved, these molecules are structurally organized in two to three Cys/His baculovirus IAP repeats (BIR) and a carboxyl-terminal RING finger [29]. Recombinant expression of IAP proteins counteracted various forms of apoptosis in vitro [30] and in vivo [31]. Recently, a novel gene encoding a structurally unique IAP apoptosis inhibitor, designated survivin has been identified. Survivin is a $\sim 16.5$-kd cytoplasmic protein containing single BIR and no RING finger, which inhibits apoptosis induced by growth factor (interleukin IL-3) withdrawal when transfected in B cell precursors [32]. At variance with bcl-2 or other IAP proteins, survivin is undetectable in adult tissues but becomes prominently expressed in all of the most common human cancers of lung, colon, breast, pancreas and prostate, in $\sim 50 \%$ of high-grade non-Hodgkin's lymphomas. Intriguingly, the coding strand of the survivin gene was highly homologous to the sequence of effector cell protease receptor - 1 (EPR-1) but oriented in the opposite direction; thus suggesting the existence of two separate genes duplicated in a head-to-head configuration [32].

In the study of Beltrami et al. in 2004, they positioned survivin - in a p53-dependent pathway that surveys the progression through multiple phases of mitosis, and linked its second functions in cytoprotection to the upstream regulation of mitochondrial-dependent apoptosis. These combined features fulfill the definition of survivin as a mitotic checkpoint required for genomic integrity and cytoprotection. They also concluded that reduction in the nuclear pool of survivin was sufficient to cause a composite deregulation of cell division, in which mitotic arrest and polyploidy was one but several defects involving centrosome replication, microtubule nucleation, and mitotic spindle assembly/stability. This phenotype was exacerbated in cells lacking the Cdk inhibitor, p21Waf1/Cip1, suggesting that unbridled Cdk activity, most notable Cdk2/4/6, cooperates with loss of survivin in deregulating the proper assembly of a bipolar mitotic apparatus [8].

A novel aspect of the survivin mitotic checkpoint uncovered was its independence on p53 [3]. Although it was previously demonstrated that survivin is one of the few known genes transcriptionally repressed by $553[5,6]$, loss of survivin resulted in up-regulation of the p53 downstream transcriptional target p21Waf1/Cip1, which also participates in p53-dependent $\mathrm{G} 2 / \mathrm{M}$ arrest, via increased p53 expression and/or activity. It is established that p53 functions in cell cycle arrest at both G1/S and G2/M transitions [33] and that this pathway is essential for genomic integrity [34]. It has been suggested that survivin may function as a novel relay of cell division defects that activates p53-dependent responses in mitotically abnormal cells, thus limiting their progression to aneuploidy. This is consistent with the role of p53 in limiting DNA endoreduplication and aneuploidy after spindle damage and suggests that p53-dependent repression of the survivin gene $[5,6]$ may further integrate this checkpoint to lower an anti-apoptotic threshold in mitotically arrested cells (8).

An apoptosis inhibitor, survivin, has recently been identified. Unlike other members of the bcl-2 and IAP gene families, survivin is selectively expressed in all the most human cancers but not in normal adult tissues [15].

The data presented define a novel role of survivin in the regulation of mitochondrial-dependent apoptosis, independently of p53. At present, we can only speculate as to the mechanistic links between survivin and mitochondrial apoptosis. This may involve modulation of an upstream caspase that perturbs mitochondrial function, i.e. caspase-2, or, alternatively, a direct effect on mitochondria, as recently proposed for one of the alternatively spliced survivin isoforms. Studies also appear to pinpoint the cytoprotective function of survivin to its cytosolic pool. Intriguingly, cytosolic, but not nuclear survivin has been shown to be phosphorylated [8].

In the study of Zhang et al., they suggested a novel cellular/tissue mechanism for initiation of colon tumorigenesis, a mechanism that suggests how APC mutation, the initiating molecular event in CRC, leads to abnormalities at cellular and tissue levels. In crypts containing mutant APC, survivin expression may become constitutive, thereby inhibiting apoptosis. In this case, mutant stem cell progeny would tend to maintain their natural, stem-cell-like phenotype as they migrate up the crypt. Thus, constitutive expression of survivin prevents apoptosis, contributes to cellular immortality, and may be a key contributing mechanism in early colonic tumorigenesis [17].

Speliotes et al., also proposed that human survivin may affect chromosomal and spindle processes and perhaps tumorigenesis via an evolutionarily conserved interaction with Aurora-like kinases [35].

In the present study, we tried to focus on the role of survivin - for the first time - in one of important cutaneous neoplasia MF (Cutaneous T-Cell Lymphoma). We found that survivin gene expression and survivin protein level was significantly high in patients with MF cases if compared to normal subjects which suggests a functional role of survivin in the pathogenesis of Cutaneous T-cell 
lymphoma in the same way it induces other cancers. Also, we have found that the survivin gene expression and its protein differ according to the site of the lesions, where the survivin gene expression showed its highest level in the back lesion and its lowest level in the chest lesion. While the survivin protein level showed its highest level in the lower limb lesion and its lowest level in the back lesion. We couldn't find an appropriate explanation for such findings.

Also, we found that survivin expression is not too much affected by the number of the lesions, as the difference between the survivin gene and protein expression in patients with single or multiple lesions is not striking.

Meanwhile, we found that survivin expression is influenced by sex of the patients. The level of survivin gene and protein expression is significantly higher in males than in females.

We have also found that, there was no significant correlation between the survivin gene and protein expression on one hand and age of the patients, size of the lesions on the other hand. Although there was no significant correlation between survivin gene expression and disease duration; the level of survivin protein expression is significantly affected by disease duration where the level increased with the increase in the disease duration.

In our study, we could not find a significant correlation between survivin gene expression and its protein level in the examined cases. Unfortunately, we could not find other reports or studies that could support, contradict nor explain our findings.

In summary, we have demonstrated that surviving targeting is an effective means to activate p53-dependent responses, block cell proliferation, and induce apoptosis resulting from survivin ablation reinforces the suitability of targeting survivin for novel cancer therapeutics [10], whose efficacy would not be affected by the p53 status of the tumor. Although the independent regulation of distinct surviving subcellular pools calls for caution in interpreting results of RNA ablation [21,24], the data presented here position the survivin pathway as a novel checkpoint mechanism at the interface between mitotic progression and apoptosis control.

Predictive and prognostic detection of survivin has been implemented in some types of cancer, and strategies for targeting surviving as a new cancer treatment are underway. Our data help to explain a previously unidentified aspect of the role of survivin in one of important cutaneous neoplasm (cutaneous T-cell lymphoma; mycosis fungoides).

We hope that in the near future further studies will be conducted to highlight the role of survivin in different skin neoplastic disorders which could influence the therapeutic strategies targeting survivin as a new cancer treatment for such neoplasms.

\section{References}

1. Hengartner MO (2000) The biochemistry of apoptosis. Nature 407: 770-776.

2. Evan GI, Vousden KH (2001) Proliferation, cell cycle and apoptosis in cancer. Nature 411: 342-348.

3. Hanahan D, Weinberg RA (2000) The hallmarks of cancer. Cell 100: 57-70.

4. Sommer KW, Schamberger CJ, Schmidt GE, Sasgary S, Cerni C (2003) Inhibitor of apoptosis protein (IAP) survivin is upregulated by oncogenic c-H-Ras. Oncogene 22: 4266-4280.
5. Mirza A, McGuirk M, Hockenberry TN, Wu Q, Ashar H, et al. (2002) Human survivin is negatively regulated by wild-type p53 and participates in p53-dependent apoptotic pathway. Oncogene 21: 2613-2622.

6. Hoffman WH, Biade S, Zilfou JT, Chen J, Murphy M (2002) Transcriptional repression of the anti-apoptotic survivin gene by wild type p53. J Biol Chem 277: 3247-3257.

7. Silke J, Vaux DL (2001) Two kinds of BIR-containing protein - inhibitors of apoptosis, or required for mitosis. J Cell Sci 114: 1821-1827.

8. Beltrami E, Plescia J, Wilkinson J (2004) Acute ablation of survivin uncovers p53-dependent mitotic checkpoint functions and control of mitochondrial apoptosis. Journal of Biological Chemistry 279: 2077-2084.

9. Uren AG, Wong L, Pakusch M, Fowler KJ, Burrows FJ, et al. (2000) Survivin and the inner centromere protein INCENP show similar cellcycle localization and gene knockout phenotype. Curr Biol 10: 1319-1328.

10. Fraser AG, James C, Evan GI, Hengartner MO (1999) Caenorhabditis elegans inhibitor of apoptosis protein (IAP) homologue BIR-1 plays a conserved role in cytokinesis. Curr Biol 9: 292-301.

11. Jiang X, Wilford C, Duensing S, Munger K, Jones G, et al. (2001) Participation of Survivin in mitotic and apoptotic activities of normal and tumor-derived cells. J Cell Biochem 83: 342-354.

12. Giodini A, Kallio MJ, Wall NR, Gorbsky GJ, Tognin S, et al. (2002) Regulation of microtubule stability and mitotic progression by survivin. Cancer Res 62: 2462-2467.

13. Fortugno P, Wall NR, Giodini A, O'Connor DS, Plescia J, et al. (2002) Survivin exists in immunochemically distinct subcellular pools and is involved in spindle microtubule function. J Cell Sci 115: 575-585.

14. Mahotka C, Wenzel M, Springer E, Gabbert HE, Gerharz CD (1999) Survivin-deltaEx3 and survivin-2B: two novel splice variants of the apoptosis inhibitor survivin with different antiapoptotic properties. Cancer Res 59: 6097-6102.

15. Smith SD, Wheeler MA, Plescia J, Colberg JW, Weiss RM, et al. (2001) Urine detection of survivin and diagnosis of bladder cancer. JAMA 285: 324-328.

16. Kim PJ, Plescia J, Clevers H, Fearon ER, Altieri DC (2003) Survivin and molecular pathogenesis of colorectal cancer. Lancet 362: 205-209.

17. Zhang T, Otevrel T, Gao Z, Gao Z, Ehrlich SM, et al. (2001) Evidence that APC regulates survivin expression: a possible mechanism contributing to the stem cell origin of colon cancer. Cancer Res 61: 8664-8667.

18. Kawasaki H, Altieri DC, Lu CD, Toyoda M, Tenjo T, et al. (1998) Inhibition of apoptosis by survivin predicts shorter survival rates in colorectal cancer. Cancer Res 58: 5071-5074.

19. Adida C, Berrebi D, Peuchmaur M, Reyes-Mugica M, Altieri DC (1998) Anti-apoptosis gene, survivin, and prognosis of neuroblastoma. Lancet 351: 882-883.

20. Chomczynski P, Sacchi N (1987) Single-step method of RNA isolation by acid guanidinium thiocyanate-phenol-chloroform extraction. Anal Biochem 162: 156-159.

21. Chard T (1990) "An introduction to radio immune assay and related techniques 4th Ed", Elsevier, Amsterdam.

22. Adida C, Crotty PL, McGrath J, Berrebi D, Diebold J, et al. (1998) Developmentally regulated expression of the novel cancer anti-apoptosis gene survivin in human and mouse differentiation. Am J Pathol 152: 43-49.

23. Vaux DL, Haecker G, Strasser A (1994) An evolutionary perspective on apoptosis. Cell 76: 777-779.

24. Oltvai ZN, Korsmeyer SJ (1994) Checkpoints of dueling dimers foil death wishes. Cell 79: 189-192.

25. Reed JC (1994) Bcl-2 and the regulation of programmed cell death. J Cell Biol 124: 1-6.

26. Yang E, Korsmeyer SJ (1996) Molecular thanatopsis: a discourse on the BCL2 family and cell death. Blood 88: 386-401.

27. LeBrun DP, Warnke RA, Cleary ML (1993) Expression of bcl-2 in fetal tissues suggests a role in morphogenesis. Am J Pathol 142: 743-753.

28. Clem RJ, Miller LK (1994) Control of programmed cell death by the baculovirus genes p35 and iap. Mol Cell Biol 14: 5212-5222. 
Citation: Nada H, Rashed L, Amin S (2016) Expression of Survivin Gene and Protein in Mycosis Fungoides. J Nurs Care 5: 339. doi: 10.4172/2167-1168.1000339

Page 6 of 6

29. Rothe M, Pan MG, Henzel WJ, Ayres TM, Goeddel DV (1995) The TNFR2-TRAF signaling complex contains two novel proteins related to baculoviral inhibitor of apoptosis proteins. Cell 83: 1243-1252.

30. Liston P, Roy N, Tamai K, Lefebvre C, Baird S, et al. (1996) Suppression of apoptosis in mammalian cells by NAIP and a related family of IAP genes. Nature 379: 349-353.

31. Hay BA, Wassarman DA, Rubin GM (1995) Drosophila homologs of baculovirus inhibitor of apoptosis proteins function to block cell death. Cell 83: 1253-1262.
32. Ambrosini G, Adida C, Altieri DC (1997) A novel anti-apoptosis gene, survivin, expressed in cancer and lymphoma. Nat Med 3: 917-921.

33. Taylor WR, Stark GR (2001) Regulation of the G2/M transition by p53. Oncogene 20: 1803-1815.

34. Zhou BB, Elledge SJ (2000) The DNA damage response: putting checkpoints in perspective. Nature 408: 433-439.

35. Speliotes EK, Uren A, Vaux D, Horvitz HR (2000) The survivin-like C. elegans BIR-1 protein acts with the Aurora-like kinase AIR-2 to affect chromosomes and the spindle midzone. Mol Cell 6: 211-223. 